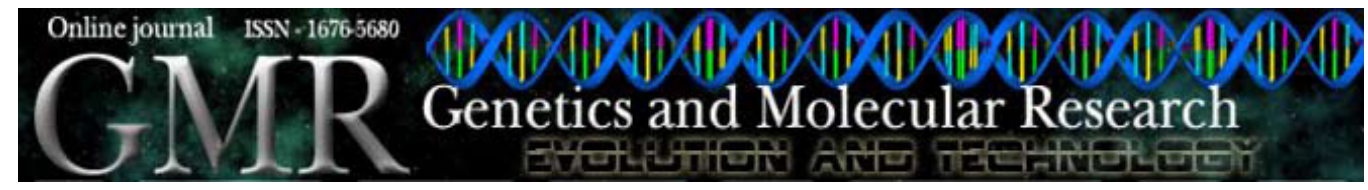

\title{
Genetic distance estimates among single cross hybrids and correlation with specific combining ability and yield in corn double cross hybrids
}

\author{
M. Balestre, J.C. Machado, J.L. Lima, J.C. Souza and L. Nóbrega Filho \\ Departamento de Biologia, Universidade Federal de Lavras, \\ Lavras, MG, Brasil \\ Corresponding author: M. Balestre \\ E-mail: marciobalestre@hotmail.com
}

Genet. Mol. Res. 7 (1): 65-73 (2008)

Received October 9, 2007

Accepted December 15, 2007

Published January 25, 2008

\begin{abstract}
The objective of the present study was to correlate the genetic distances (GD) of single cross hybrids with yield, heterosis and specific combining ability (SCA) in the double cross hybrid synthesis. For this, 10 single cross commercial hybrids were used from different companies, and all the possible double hybrids were synthesized by a complete dialell. The hybrids were assessed in 15 locations in the 2005/2006 agricultural season, using the randomized complete block design with three repetitions. DNA was extracted from the single cross hybrids and 20 simple sequence repeat primers were used, nine of which were linked to the quantitative trait loci. It was ascertained that the single hybrids were superior in general to the double cross hybrids and that yield was highly correlated with heterosis and SCA $(r=0.75$ and 0.82 , respectively). There was no significant correlation between yield and GD $(r=0.25)$, but this index was at the limit of significance. There was a medium correlation between GD and heterosis $(r=0.40)$ and GD and SCA $(r=0.38)$. The intergroup hybrids placed by genetic grouping were generally more productive than intragroup hybrids, and the hybrids with GD greater than 0.84 had the maximum heterosis and SCA. It was concluded that the markers were efficient in placing
\end{abstract}


hybrids in different heterosis groups and were also useful in eliminating the most negative heterosis and SCA.

Key words: Dialell; SSR; Heterotic groups; Molecular markers

\section{INTRODUCTION}

In corn breeding programs it is necessary to place populations in different heterotic groups when the objective is line extraction for interpopulation hybrid synthesis. The specific combining ability (SCA) of these populations is a very useful parameter for the breeder in choosing populations for line extraction to obtain interpopulation hybrids. Knowledge of the effects of the general combining ability (GCA) and SCA helps in testing hypotheses and predicting crosses and is important for understanding the genetic structure of lines and populations (Hallauer and Miranda Filho, 1995).

Line extraction from populations derived from commercial single cross hybrids has been shown to be viable (Bison et al., 2003). The advantage of this technique compared to obtaining lines from open pollination varieties lies mainly in the fact that populations derived from single cross hybrids are tested in several environments, that is, they are adapted, highly productive and have a great proportion of favorable alleles already fixed. Furthermore, the pairs with better SCA and greater heterosis estimates will be the most promising in obtaining lines for interpopulation hybrid synthesis.

The theory of quantitative genetics describes a correlation between parental divergence and the heterosis estimates (Falconer and Mackay, 1997). Thus, heterosis is a function of the square of the differences between the allele frequencies in the parents, that is, the genetic divergence and also the dominance effect of the alleles controlling the traits in question (Falconer, 1981). However, the data obtained with molecular markers to date are not conclusive regarding this correlation.

Amorim et al. (2006) worked with three $\mathrm{S}_{0}$ populations derived from different single cross hybrids and selected the two most and the two least productive inter- and intrapopulation hybrids from a total of 163 assessed hybrids. The 48 parent lines of these hybrids were genotyped with 47 simple sequence repeat (SSR) primers. These authors obtained high correlation between grain yield and genetic divergence for interpopulation hybrids $(r=0.84)$, but this correlation was low for intrapopulation hybrids, showing that the markers would be efficient in predicting hybrids derived from different heterotic groups.

Melo et al. (2001) worked with 10 commercial single cross hybrids of different origins and showed strong correlation among the per se performances and the SCA (0.72) and the per se performances and heterosis (0.92). However, the correlation between SCA and distance was not significant (-0.09).

As there are many options of single cross hybrids, it was impossible to assess all the possible double cross hybrids. An alternative would be the choice of crosses based on their genetic divergence, estimated by molecular markers (Árcade et al., 1996; Melchinger, 1999). Among the molecular markers, microsatellites or SSR are outstanding, which have been the most promising for studies of genetic diversity and hybrid prediction because they demonstrate Mendelian heredity and codominant performance, that is, they permit the identification of homozygote and heterozygote genotypes in the population. Furthermore, there is a large set of microsatellites available for use in corn, many of them identified as being associated with 
grain yield quantitative trait loci (QTL) (Sibov et al., 2003).

The objective of the present study was to correlate the genetic distance (GD) of single hybrids of different origins with yield, SCA and heterosis to obtain double hybrids.

\section{MATERIAL AND METHODS}

A total of 55 treatments were assessed, 10 commercial single cross hybrids used as parents (Table 1) and 45 double cross hybrids resulting from a complete dialell. The seeds of the double cross hybrids were obtained from the Biology Department, Federal University of Lavras. The experiments were carried out in 15 locations in the 2005/2006 agricultural season. The treatments were assessed using a randomized complete block design. In all the environments, the plots consisted of two 3-m rows with three repetitions, using a population density equivalent to 55,000 plants per hectare. The other crop treatments were those normally used by producers for

\begin{tabular}{|c|c|c|c|}
\hline Hybrid & Company & Grain texture & Cycle \\
\hline 1 & Monsanto & Dent & SMP \\
\hline 2 & Pioneer & Flint & SMP \\
\hline 3 & Nidera Sementes & Flint & SMP \\
\hline 4 & Monsanto & Dent & SMP \\
\hline 5 & Dow AgroSciense & Dent & $\mathrm{P}$ \\
\hline 6 & Monsanto & Dent & $\mathrm{P}$ \\
\hline 7 & Pioneer & Flint & SMP \\
\hline 8 & Dow AgroScience & Flint & $\mathrm{P}$ \\
\hline 9 & Pioneer & Dent & SMP \\
\hline 10 & Monsanto & Dent & SMP \\
\hline
\end{tabular}

the corn crop. The unhusked corn ear yield $(\mathrm{kg} / \mathrm{ha})$ was assessed, corrected for $13 \%$ moisture.

Method II proposed by Griffing (1956) was used for the individual dialell analyses, where all the possible crosses were assessed including the parents. The joint dialell analysis was carried out according to Zhang et al. (2005).

Twenty seeds of each of the 10 single cross hybrids were sown in 128-well trays in a greenhouse, and after emergence of the second pair of leaves, the DNA was extracted according to Saghai-Maroof et al. (1984). The extracted DNA was quantified in a fluorimeter and diluted to a $10 \mathrm{ng} / \mathrm{mL}$ concentration. The material was then genotyped with 20 microsatellite primers, nine of which were linked to the QTL. The SSR reactions were prepared to a final volume of $11.06 \mu \mathrm{L}$ consisting of: $2.25 \mu \mathrm{L}$ genomic DNA, $1.96 \mu \mathrm{L}$ reaction buffer $(50 \mathrm{mM}$ Tris, $2.0 \mathrm{mM}$ $\mathrm{MgCl}_{2}, 20 \mathrm{mM} \mathrm{KCl}, 250 \mathrm{mg} / \mathrm{mL}$ bovine serum albumin, 1\% Ficoll 400; $1 \mathrm{mM}$ tartrazine), $100 \mu \mathrm{M}$ dNTPs, $4.45 \mu \mathrm{L}$ pure water, $0.6 \mu \mathrm{L}$ Taq DNA polymerase, and $0.2 \mu \mathrm{M}$ of each primer (forward and reverse). The amplifications were carried out in a Mastercycler Gradient thermocycler, using $0.2-\mathrm{mL}$ microtubes. The initial denaturation was at $95^{\circ} \mathrm{C}$ for $2 \mathrm{~min}$ followed by 32 cycles each consisting of denaturation at $95^{\circ} \mathrm{C}$ for $20 \mathrm{~s}$, annealing at $55^{\circ} \mathrm{C}$ for $20 \mathrm{~s}$, and a final extension at $72^{\circ} \mathrm{C}$ for $20 \mathrm{~s}$. The fragments were separated on agarose gels (Invitrogen), at $3 \%$ concentration and prepared with $0.5 \mathrm{X}$ TBE buffer. Electrophoresis was carried out at a constant $100 \mathrm{~V}$ for approximately $3 \mathrm{~h}$ in a horizontal cube. After electrophoresis, the gels were treated 
with ethidium bromide $(0.5 \mu \mathrm{g} / \mathrm{mL})$ for $20 \mathrm{~min}$ and visualized under ultraviolet light. The images were captured by an EDAS 290 digital camera (Kodak Digital Science). A binary matrix was constructed using the SSR results, from which the GDs of each hybrid were calculated using the Roger modified distance (Wright, 1978), with the NTSYS-PC 2.1 program (Rohlf, 2000).

The distance matrix was grouped by the UPGMA (unweighted pair-group method using the arithmetic average), and then the dendrogram was obtained that was an indication of kinship among the hybrids analyzed. The cophenotypic correlation was calculated between the GD matrix and the cophenotypic value matrix to verify the consistency of the grouping.

The Pearson (r) correlation was used for the correlation study, and then the correlation between GD, heterosis, SCA, and yield was analyzed. The significance of the associations among matrices (r) was tested by the Mantel statistic (1967).

\section{RESULTS}

Significant differences were detected $(\mathrm{P} \leq 0.01)$ for all the sources of variation in the joint dialell analysis involving the 15 environments (Table 2). It was, therefore, inferred that the parents under assessment differed in their mean allele frequencies, contributing differently to the crosses in which they were involved and that the hybrid combinations showed different performances from that expected only because of the GCA effects. The significance of the variation sources GCA $x$ A and SCA x E indicated that both the effects of the GCA and SCA were not coincident in the environments assessed.

Table 2. Summary of the joint analysis of variance for shucked corn ear yield $(\mathrm{kg} / \mathrm{ha})$, with breakdown of the hybrid effect in the general combining ability (GCA) and specific combining ability (SCA) obtained by the dialell of 10 single cross hybrids (SCH) assessed in 15 environments, in the 2005/2006 agricultural season.

\begin{tabular}{lrc}
\hline Source & d.f. & MS \\
\hline Environments (E) & 14 & $794873096^{*}$ \\
Repetitions/E & 29 & $6585709^{*}$ \\
Hybrids (H) & 54 & $18097540^{*}$ \\
GCA & 9 & $39020099^{*}$ \\
SCA & 45 & $14193119^{*}$ \\
H x E & 756 & $2554880^{*}$ \\
GCA x E & 126 & $5159456^{*}$ \\
SCA x E & 630 & $2033964^{*}$ \\
Error & 1566 & $1289652^{*}$ \\
CV (\%) & & 13.9 \\
$\mathrm{R}^{2}(\%)$ & & 87.6 \\
Mean (kg/ha) & & 8162 \\
Mean SCH (kg/ha) & & 8643 \\
Mean DCH (kg/ha) & & 8082 \\
\hline Significant at $1 \%$ probality
\end{tabular}

*Significant at $1 \%$ probability by the $\mathrm{F}$ test. d.f. $=$ degrees of freedrom; $\mathrm{MS}=$ mean square; $\mathrm{CV}=$ coefficient of variation; $\mathrm{SCH}=$ single cross hybrids; $\mathrm{DCH}=$ double cross hybrids.

The estimates of the GCA $\left(\hat{\mathrm{g}}_{\mathrm{i}}\right)$ of the hybrids assessed ranged from -358.1 to 540.4. The highest estimates were obtained by hybrids 6 and 2 inferring that these hybrids have a higher frequency of favorable alleles for yield. The SCA $\left(\hat{\mathrm{s}}_{\mathrm{ii}}\right)$ estimates ranged from 1532.7 to 550.3 , and the largest and smallest estimates were observed in hybrids $1 \times 10$ and $1 \times 8$, respectively (Table 3 ). 


\begin{tabular}{|c|c|c|c|c|c|c|c|c|c|}
\hline Hybrid & PED (kg/ha) & $\mathrm{G}_{\mathrm{i}}$ & & & Hybrid & PED (kg/ha) & $\mathrm{S}_{\mathrm{i}}$ & $\mathrm{H}$ & GD \\
\hline 1 & $9013^{b}$ & 22.6 & & & $3 \times 4$ & $7790^{\mathrm{e}}$ & -26.2 & -765 & 0.87 \\
\hline 2 & $9054^{\mathrm{b}}$ & 359.4 & & & $3 \times 5$ & $6531^{g}$ & -1002.9 & -1168 & 0.84 \\
\hline 3 & $7923^{e}$ & -275.7 & & & $3 \times 6$ & $7907^{e}$ & -525.3 & -882.5 & 0.84 \\
\hline 4 & $9187^{b}$ & -123.3 & & & $3 \times 7$ & $8007^{\mathrm{e}}$ & 34 & -389.5 & 0.91 \\
\hline 5 & $7475^{e}$ & -358.1 & & & $3 \times 8$ & $8242^{d}$ & 431.3 & 187 & 0.88 \\
\hline 6 & $9656^{\mathrm{a}}$ & 540.4 & & & $3 \times 9$ & $7783^{e}$ & -96 & -291 & 0.92 \\
\hline 7 & $8870^{c}$ & 69.6 & & & $3 \times 10$ & $8060^{d}$ & 169.2 & -321 & 0.91 \\
\hline 8 & $8187^{d}$ & 97.8 & & & $4 \times 5$ & $7971^{\mathrm{e}}$ & 250.5 & -360 & 0.89 \\
\hline 9 & $8225^{\mathrm{d}}$ & 78.5 & & & $4 \times 6$ & $8388^{c}$ & -178.9 & -1033.5 & 0.89 \\
\hline 10 & $8839^{c}$ & 58.6 & & & $4 \times 7$ & $7163^{f}$ & -965 & -1865.5 & 0.84 \\
\hline Hybrid & $\operatorname{PED}(\mathrm{kg} / \mathrm{ha})$ & $\mathrm{S}_{\mathrm{i}}$ & $\mathrm{H}$ & GD & $4 \times 8$ & $7718^{e}$ & -226.1 & -969 & 0.87 \\
\hline $1 \times 2$ & $8973^{b}$ & 365.1 & -60.5 & 0.77 & $4 \times 9$ & $8497^{c}$ & 542.9 & -209 & 0.95 \\
\hline $1 \times 3$ & $8243^{d}$ & 302.9 & -225 & 0.87 & $4 \times 10$ & $7004^{f}$ & -1009.3 & -2009 & 0.76 \\
\hline $1 \times 4$ & $6678^{\mathrm{g}}$ & -1376.2 & -2422 & 0.65 & $5 \times 6$ & $8397^{c}$ & 2.7 & -168.5 & 0.82 \\
\hline $1 \times 5$ & $7929^{\circ}$ & 79.5 & -315 & 0.89 & $5 \times 7$ & $8137^{d}$ & 278.9 & -35.5 & 0.89 \\
\hline $1 \times 6$ & $9036^{\mathrm{b}}$ & 237.4 & -298.5 & 0.95 & $5 \times 8$ & $7723^{e}$ & -8.6 & -108 & 0.88 \\
\hline $1 \times 7$ & $7958^{\mathrm{e}}$ & -325.6 & -983.5 & 0.77 & $5 \times 9$ & $7956^{\mathrm{e}}$ & 176.7 & 106 & 0.71 \\
\hline $1 \times 8$ & $8655^{\mathrm{c}}$ & 550.3 & 55 & 0.94 & $5 \times 10$ & $8177^{d}$ & 405.5 & 20 & 0.85 \\
\hline $1 \times 9$ & $8264^{d}$ & 120.6 & -355 & 0.92 & $6 \times 7$ & $9344^{a}$ & 532 & 81 & 0.84 \\
\hline $1 \times 10$ & $6635^{\mathrm{g}}$ & -1532.7 & -2291 & 0.76 & $6 \times 8$ & $8272^{\mathrm{d}}$ & -334.2 & -649.5 & 0.71 \\
\hline $2 \times 3$ & $8341^{\mathrm{d}}$ & 75 & -147.5 & 0.87 & $6 \times 9$ & $8320^{d}$ & -358.7 & -620.5 & 0.74 \\
\hline $2 \times 4$ & $8875^{c}$ & 451.1 & -245.5 & 0.72 & $6 \times 10$ & $8868^{c}$ & 216.2 & -379.5 & 0.81 \\
\hline $2 \times 5$ & $7971^{\mathrm{e}}$ & -218.8 & -293.5 & 0.87 & $7 \times 8$ & $7538^{e}$ & -630.1 & -990.5 & 0.85 \\
\hline $2 \times 6$ & $8618^{c}$ & -440.3 & -737 & 0.88 & $7 \times 9$ & $8019^{e}$ & -150.5 & -528.5 & 0.84 \\
\hline $2 \times 7$ & $8738^{c}$ & 140.4 & -224 & 0.85 & $7 \times 10$ & $8101^{d}$ & -61.8 & -753.5 & 0.67 \\
\hline $2 \times 8$ & $8217^{d}$ & -236.3 & -403.5 & 0.92 & $8 \times 9$ & $7885^{\mathrm{e}}$ & -124.6 & -321 & 0.82 \\
\hline $2 \times 9$ & $8008^{e}$ & -471.7 & -631.5 & 0.82 & $8 \times 10$ & $8157^{d}$ & 153.2 & -356 & 0.74 \\
\hline $2 \times 10$ & $8597^{c}$ & 77.5 & -349.5 & 0.85 & $9 \times 10$ & $8004^{e}$ & -37.3 & -528 & 0.74 \\
\hline
\end{tabular}

Means followed by the same letter do not differ by the Scott and Knott test at 5\% probability.

Parents that, in addition to having high $\hat{\mathrm{g}}_{\mathrm{i}}$ estimates, produced superior hybrid combinations were identified. They included the combinations $6 \times 7,1 \times 2$ and $2 \times 6$, which showed high yield, high favorable allele frequency of their parents and the possibility of satisfactory heterosis exploitation (Table 3 ).

It was ascertained in the diversity study that the number of polymorphic alleles obtained by the genotyping of the 10 single hybrids used in this study was 83 , with an average of 4.15 alleles per locus, similar to that obtained by Amorim et al. (2006).

The average GD of the 10 single cross hybrids was 0.84 . This relatively high distance was due to the use of hybrids from four different companies, that is, of different origins. The greatest GDs were detected in the $4 \times 9(0.95)$ and $1 \times 6(0.95)$ hybrids, both with high yields. It was also observed that hybrids with smaller GD $(0.65)$ produced a low yield double cross hybrid $(1 \times 4)$. These hybrids were derived from the same company and probably had parents in common or very close in their genetic constitution.

The dendrogram of the GDs calculated by the UPGMA method based on the microsatellite data showed a high cophenetic value $(\mathrm{r}=0.78, \mathrm{P}<0.0001 ; 10,000$ permutations). According to Vaz Patto et al. (2004), an ideal index for this type of correlation would be greater than 0.56.

The cut-off point on the dendrogram adopted in this study was 0.84 among all the hybrids genotyped with microsatellites. The dendrogram shows the formation of three different 
heterotic groups. The first group included three of the four hybrids from the Monsanto Company and two of the three hybrids from the Pioneer Company. In group 2 there were 2 hybrids from the Dow AgroScience Company with the rest of the hybrids from the Monsanto and Pioneer companies. In the third group, there was only the hybrid from the Nidera Sementes Company, showing that the microsatellites were efficient in distinguishing the heterotic groups (Figure 1).

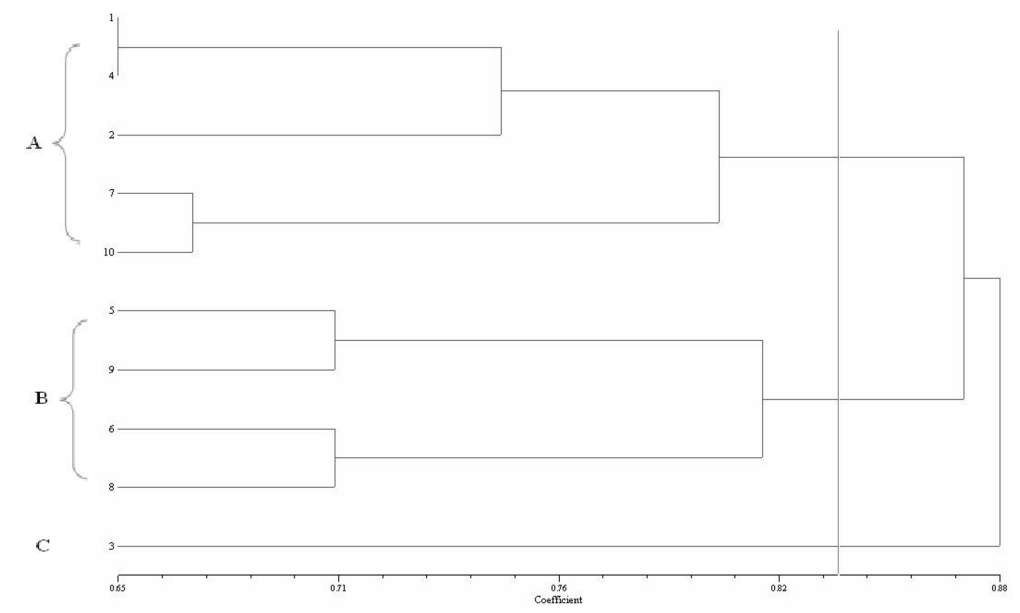

Figure 1. Dendrogram of the de Roger's genetic distance by the UPGMA method, where A, B and C were the heterotic groups among single cross hybrids.

Analysis of the dendrogram and the yields of the intragroup and intergroup double cross hybrids showed that the greatest yield originated from hybrids in different heterotic groups (6 (B) x 7 (A) and 6 (B) x 1 (A)) with 9344 and $9036 \mathrm{~kg} / \mathrm{ha}$, respectively, and the lowest yields occurred in intragroups (1 x 4 (A) and 1 x 10 (A)) with 6678 and $6635 \mathrm{~kg} / \mathrm{ha}$. The average of the $\mathrm{AB}$ intergroup hybrids was $8276 \mathrm{~kg} / \mathrm{ha}$, with the hybrids in group A with 7872 $\mathrm{kg} / \mathrm{ha}$ and in group B with $8092 \mathrm{~kg} / \mathrm{ha}$. It is important to mention that group C was not added to the table because it consisted of a single genotype (Table 4).

Table 4. Data regarding yield (Y), heterosis (H) and specific combining ability (SCA) of the double hybrids placed in the A and B heterosis groups by the UPGMA grouping of the Roger modified distance.

\begin{tabular}{lccc}
\hline Source & \multicolumn{3}{c}{ Groups } \\
\cline { 2 - 4 } & $\mathrm{A}$ & $\mathrm{B}$ & $\mathrm{AB}$ \\
\hline $\mathrm{Y}^{1}(\mathrm{~kg} / \mathrm{ha})$ & 8875 & 8387 & 9344 \\
$\mathrm{Y}^{2}(\mathrm{~kg} / \mathrm{ha})$ & 6635 & 7723 & 7538 \\
Mean yield & 7872 & 8092 & 8276 \\
$\mathrm{H}^{1}$ & -60 & 106 & 81 \\
$\mathrm{H}^{2}$ & -2422 & -649 & -1034 \\
Mean H & -1120 & -294 & -413 \\
SCA & 451 & 178 & 550 \\
SCA $^{2}$ & -1533 & -358.7 & -630 \\
Mean SCA & -424 & -108 & 38.85 \\
GD $^{1}$ & 0.85 & 0.88 & 0.95 \\
GD $^{2}$ & 0.65 & 0.71 & 0.74 \\
Mean GD & 0.77 & 0.78 & 0.87 \\
\hline
\end{tabular}

${ }_{1,2}$ Maximum and minimum, respectively. GD $=$ genetic distance. 
Table 5 shows the correlations between the Roger modified distance and yield, heterosis, and SCA. High and significant correlation was observed for yield and heterosis $(\mathrm{r}=$ $0.75 ; \mathrm{P} \leq 0.01$ ). This fact was expected, because most double cross hybrids yielded less than the mean of the parental genotypes and as the per se yield of each double hybrid was low, negative heterosis values were observed. Maximum heterosis is exploited in the single hybrid, but, as observed, some double hybrids obtained positive heterosis, and the maximum heterosis was observed in the intergroup hybrids (BC).

\begin{tabular}{|c|c|c|c|}
\hline Source & $\mathrm{r}$ & Mantel r (1\%) & Mantel r (5\%) \\
\hline PROD x H & $0.75^{*}$ & $0.38^{+}$ & $0.26^{+}$ \\
\hline PROD x SCA & $0.82 *$ & $0.36^{+}$ & $0.25^{+}$ \\
\hline $\mathrm{H} \times \mathrm{SCA}$ & $0.92^{*}$ & $0.38^{+}$ & $0.27^{+}$ \\
\hline RMD x PROD & $0.25^{\mathrm{ns}}$ & $0.34^{\mathrm{ns}}$ & $0.251^{\text {ns }}$ \\
\hline RMD x H & $0.40^{*}$ & $0.37^{+}$ & $0.26^{+}$ \\
\hline RMD $\times$ SCA & $0.38^{*}$ & $0.36^{+}$ & $0.25^{+}$ \\
\hline
\end{tabular}

${ }^{*}$ Significant at 1 and $5 \%$ probability by the $t$-test.

${ }^{+}$Significant at 1 and 5\% probability by the Mantel test based on 10,000 simulations.

In this experiment, a highly significant correlation was observed among the heterosis and $\mathrm{SCA}(\mathrm{r}=0.92 ; \mathrm{P} \leq 0.01)$, that is, as the value of the heterosis increased, the value of the SCA also increased.

High correlation was also observed between yields and SCA $(r=0.82 ; \mathrm{P} \leq 0.01)$, which was expected due to the greater importance observed of the genes with a non-additive effect, and the quadratic component referring to SCA $(\hat{\phi})$ was 4.1 times greater compared to the GCA $(\hat{\phi})$.

The correlation among GDs and yield was positive, but not significant $(\mathrm{r}=0.25, \mathrm{P}>$ $0.05)$. However, by the Mantel critical $r(P \leq 0.05)$, the positive limit was 0.251 , inferring that the correlation index was very close to significance (Table 5).

There was medium and significant correlation between distances $\mathrm{x}$ heterosis $(\mathrm{r}=0.40$; $\mathrm{P} \leq 0.01)$ and distance $\mathrm{SCA}(\mathrm{r}=0.38 ; \mathrm{P} \leq 0.01)($ Table 4$)$. These data are in line with those reported by Benchimol et al. (2000), Reif et al. (2003) and Guimarães et al. (2007), who obtained positive and significant correlations.

\section{DISCUSSION}

The intergroup hybrids placed by genetic grouping were generally more productive. According to Hallauer and Miranda Filho (1988), line crosses derived from different heterotic groups will present superior performance compared to those hybrids formed by crossing the lines of the same group, and in this study it was observed that this fact can also be extrapolated to crossing hybrids inter- and intrapopulation. This result was not observed in the crossings derived of hybrid 3 , although this hybrid is classified in a different heterotic group. This occurred because the performance of the hybrid depends not only on divergence, but also on the contribution of the loci in an already fixed homozygosis, that is, on the mean of the parents. However divergent a hybrid or line may be, if it does not have a high favorable allele frequency it will only with difficulty produce a high performance $\mathrm{F}_{1}$, and it was observed that this hybrid had low yield and low GCA. Further- 
more, it was not possible to compare the crossings derived from this parental because group C consisted of a single genotype (Figure 1).

The maximum heterosis was also observed in the intergroup hybrids. This fact may be correlated with the complementation of the loci among these hybrids, that is, of the divergence among them as observed in Table 3, only one crossing showed positive heterosis with low divergence between the parents. It was, therefore, inferred that the markers were efficient in placing hybrids in different heterotic groups, and in most cases the intergroup double hybrids were superior to the intragroup double cross hybrids.

The high correlation among heterosis and SCA observed in this study shows that the two parameters were efficient in the choice of parents or populations (Hallauer and Miranda Filho, 1995; Falconer and Mackay, 1997). According to Falconer (1981), heterosis can be explained by divergence and also by the effect of dominance of the alleles that control the trait in question, as SCA can be explained by genes that exhibit non-additive effects (dominance and epistasis) (Vencovsky, 1987; Hallauer and Miranda Filho, 1988). Thus, by the theory of quantitative genetics, both parameters would be correlated, and in this experiment these parameters were highly correlated.

Correlation was not observed in similar studies between hybrid yield and their GDs (Melo et al., 2001; Parentoni et al., 2001; Guimarães et al., 2007). In a survey of 54 studies involving several crops, Dias et al. (2004) reported that 26 contained negative or inconclusive correlations between distances and yield. This low correlation can be explained because of the allele frequencies of the parents not being negatively correlated, low heritability of the trait and low association of markers with QTL that influence the trait (Bernardo, 1992). Melchinger (1999) stated that the linking phase between the QTL and the parent marker was important, and if the marker and the QTL were in different linking phases, low correlation would occur. According to this author, this occurs mainly in crosses of parents of different heterotic groups.

Four of the five estimates of positive heterosis occurred with high GDs (GD $\geq 0.84$ ), and the greatest heterosis observed corresponded to the $3 \times 8$ hybrid with GD $=0.88$ (Table 3 ). In contrast, $100 \%$ of the five highest negative heterosis estimates corresponded to genotypes with $\mathrm{GD} \leq 0.84$, where extreme negative heterosis was observed in the $1 \times 4$ hybrid with GD $=0.65$ which was the smallest distance observed among the genotypes. It was inferred, therefore, that individuals selected above 0.84 would have higher heterosis indices, thus showing the usefulness of the marker in choosing the genotype.

Regarding SCA, of the five highest estimates for this parameter, four were of individuals derived from parents with GD $\geq 0.84$ and the highest estimate was observed in the $1 \times 8$ hybrid with GD $=0.94$ (Table 3 ). Of the five most negative estimates for this parameter, four were from individuals with GD $\leq 0.84$, and extreme negative SCA was seen with the $1 \times 10$ hybrid with GD $=0.76$.

Due to the high correlation between heterosis and SCA with yield, it was concluded that the two parameters would be useful in the choice of parents for line extraction for interpopulation hybrids. Generally, the molecular markers (SSR) were efficient in identifying the greater value of heterosis and SCA, and consequently in eliminating the worst estimates for those parameters. Thus, in this study, through the use of markers, it was possible to identify the promising combinations, mainly in intergroup hybrids.

\section{ACKNOWLEDGMENTS}

The authors thank FAPEMIG, Professor Dr. João Bosco dos Santos and the Genetic 
Molecular Laboratory at the Department of Biology at the Federal University of Lavras for the reagents, and Professor Dr. Anete Pereira de Souza (CBMEG/UNICAMP) for the primers.

\section{REFERENCES}

Amorim EP, Amorim UBO, Santos JB, Souza AP, et al. (2006). Genetic distance based on SSR and grain yield of inter an intrapopulational maize single cross hybrids. Maydica 51: 507-513.

Árcade A, Faivre-Rampant P, Le Guerroué B, Paques LE, et al. (1996). Heterozigosity and hybrid performance in larch. Theor. Appl. Genet. 93: 1274-1281.

Benchimol LL, Souza CL Jr, Garcia AAF, Kono PMS, et al. (2000). Genetic diversity in tropical maize inbred lines: heterotic group assignment and hybrid performance determined by RFLP markers. Plant Breeding 119: 491-496.

Bernardo R (1992). Relationship between single cross performance and molecular marker heterozygosity. Theor. Appl. Genet. 83: 628-634.

Bison O, Ramalho MAP and Raposo FV (2003). Potencial de híbridos simples de milho para a extração de linhagens. Cienc. Agrotecn. 27: 348-355.

Dias LA, Picoli EA, Rocha RB and Alfenas AC (2004). A priori choice of hybrid parents in plants. Genet. Mol. Res. 3: 356-368.

Falconer DS (1981). Introduction to quantitative genetics. Longman, London.

Falconer DS and Mackay TF (1997). Introduction to quantitative genetics. Longman, London.

Griffing BA (1956). Concept of general and specific combining ability in relation to diallel crossing systems. Aust. J. Biol. Sci. 9: 463-493.

Guimarães OS, Paterniani MEAGZ, Luders RR, Souza AP, et al. (2007). Correlação da heterose de híbridos de milho com divergência genética entre linhagens. Pesq. Agropec. Bras. 42: 811-816.

Hallaeur AR and Miranda Filho JB (1988). Quantitative genetics in maize breeding. Iowa State University Press, Ames.

Hallaeur AR and Miranda Filho JB (1995). Quantitative genetics in maize. Iowa State University Press, Ames.

Hallauer AR and Miranda Filho JB (1998). Quantitative genetics in maize breeding. 2nd edn. Iowa State University Press, Ames.

Mantel N (1967). The detection of disease clustering and a generalized regression approach. Cancer Res. 27: 209-220.

Melchinger AE (1999). Genetic diversity and heterosis. In: The genetics and exploitation of heterosis in crops (Coors JG and Pandey S, eds.). ASA (American Society of Agronomy Inc.), Madison, 99-118.

Melo WMC, Pinho RGV and Pereira DF (2001). Capacidade combinatória e divergência genética entre híbridos comerciais de milho. Cien. Agrotecn. 25: 821-830.

Parentoni SN, Magalhães JV, Pacheco CAP, Santos MX, et al. (2001). Heterotic groups based on yield-specific combining ability data and phylogenic relationship determined by RAPD markers for 28 tropical maize open pollinated varieties. Euphytica 121: 197-208.

Reif JC, Melchinger AE, Xia XC, Warburton ML, et al. (2003). Genetic distance based on simple sequence repeats and heterosis in tropical maize populations. Crop Sci. 43: 1275-1282.

Rohlf FJ (2000). Numerical taxonomy and multivariate analysis system. Exeter Software, New York.

Saghai-Maroof MA, Soliman KM, Jorgensen RA and Allard RW (1984). Ribosomal DNA spacer-length polymorphisms in barley: Mendelian inheritance, chromosomal location, and population dynamics. Proc. Natl. Acad. Sci. USA 81: 8014-8018.

Sibov ST, de Souza CL Jr, Garcia AA, Silva AR, et al. (2003). Molecular mapping in tropical maize (Zea mays L.) using microsatellite markers. 2. Quantitative trait loci (QTL) for grain yield, plant height, ear height and grain moisture. Hereditas 139: 107-115.

Vaz Patto MC, Satovic Z, Pêgo S and Fevereiro P (2004). Assessing the genetic diversity of Portuguese maize germplasm using microsatellite markers. Euphytica 137: 63-72.

Vencovsky R (1987). Herança quantitativa. In: Melhoramento e produção do milho (Paterniani E and Viégas GP, eds.). Vol. 2. Fundação Cargill, Campinas, 137-214.

Wright S (1978). Evolution and the Genetics of Populations. Variability Within and Among Natural Populations. University of Chicago Press, Chicago.

Zhang Y, Kang MS and Lamkey KR (2005). Diallel-SAS05: a comprehensive program for Griffing's and GardnerEberhart analyses. Agron. J. 97: 1097-1106. 